\title{
STUDY OF THE PROPERTIES AND CELLS GROWTH ON ANTIBACTERIAL ELECTROSPUN POLYCAPROLACTONE/CEFUROXIME SCAFFOLDS
}

\author{
Budimir Mijovic ${ }^{1}$, Emilija Zdraveva ${ }^{1 *}$, Emi Govorčin Bajsić ${ }^{2}$, Igor Slivac ${ }^{3}$, Iva Dekaris ${ }^{4}$, Tamara Holjevac Grgurić \\ Tea Zubin Ferri ${ }^{6}$ \\ 1 University of Zagreb Faculty of Textile Technology, Department of Fundamental Natural and Engineering Sciences, Prilaz baruna Filipovića 28a, \\ 10000 Zagreb, Croatia \\ 2 University of Zagreb Faculty of Chemical Engineering and Technology, Department of Polymer Engineering and Organic Chemical Technology, Marulićev \\ $\operatorname{Trg}$ 19, 10000 Zagreb, Croatia \\ 3 University of Zagreb Faculty of Food Technology and Biotechnology, Department of Biochemical Engineering, Pierottijeva ul. 6, 10000 Zagreb, Croatia \\ 4 Specialty Eye Hospital Svjetlost, Heinzelova ul. 39, 10000 Zagreb and Department of Ophthalmology Medical Faculty, University of Rijeka, Braće \\ Branchetta 20/1, 51000 Rijeka, Croatia \\ 5 University of Zagreb, Faculty of Metallurgy, Department of Physical Metallurgy, Aleja narodnih heroja 3, Sisak, 44000, Croatia \\ 6 Materials' Research Center METRIS, Zagrebačka 30, 52100 Pula, Croatia \\ ${ }^{*}$ Correspondence to: emilija.zdraveva@ttf.hr
}

\begin{abstract}
:
Electrospun materials are good candidates for the design of tissue regeneration scaffolds as they can simulate the natural surroundings of tissue cells. The study proposes electrospun polycaprolactone (PCL)/cefuroxime (CFU) scaffolds for human cell culture and investigates the influence of the antibiotic content on scaffold morphology, thermal and mechanical properties. The increase in the CFU concentration resulted in the reduction of fiber diameter and number of deformations. It also influenced the reduction of scaffold thermal enthalpies and improved scaffold break strength. With regard to cell growth, the scaffolds showed precedence in greater colonization of the HeLa cells. Finally, these scaffolds showed compatibility with standard human cell lines, and thus they can be used for the repair of damaged tissues.
\end{abstract}

\section{Keywords:}

Electrospun, scaffolds, PCL, Cefuroxime, SEM, DSC, tensile behavior, human cells

\section{Introduction}

Electrospinning is a simple and promising technique for the design and production of biomedical products, among which are tissue engineering scaffolds. Due to the severe lack of organ donors and possible tissue inflammation after transplantation, electrospun scaffolds are promising alternative substitutes that can provide tissue repair and potential organ in vitro growth [1, 2] (Figure 1). In electrospinning, a polymer solution is stretched under the influence of an electric field and further bended to finally form ultrafine filaments collected on an opposite electrode in the shape of a nonwoven material $[1,3]$.

The advantage of an electrospun scaffold comes from the nanofibrous structure with large surface area for proteins adsorption, thus providing more binding sites for tissue cell receptors [5]. The porous structure also provides release and exchange of biomolecules and nutrients [6]. In wound healing, it can also prevent wound desiccation by liquid exudation, controlled evaporation, excellent oxygen permeability and promoted fluid drainage capacity, as well as microorganism invasion inhibition [7]. Apart from the good physical structure of the electrospun scaffolds, the same can be further functionalized for additional cell support. One of the functionalizations includes incorporation of a medicine for controlled therapies. The investigations reported both: drug effect and cultured cells, adhesion, growth and proliferation. When polycaprolactone (PCL)/poly(trimethylene carbonate) (PTMC) was electrospun with shikonin, the drug experienced fast release initial stage, followed by a gradual release that sustained for over $48 \mathrm{~h}$. The shikonin release rates also depended on the PTMC and its own concentration [8]. Another study reported on the encapsulation of the drug paclitaxel in electrospun poly-(D,L-lactide-coglycolide) (PLGA) for the treatment of malignant glioma. The electrospun PLGA/paclitaxel showed sustained release of the drug for over 80 days with small initial burst effect. The release effect was faster in the case of submicrofibers compared with the microfiber materials. In vivo studies of mice model with glioma showed inhibition of the tumor cells as well [9]. Similarly, electrospun polylactide (PLA)/pearl powder was loaded with the antitumor drug doxorubicin hydrochloride (DOX). It was reported that the presence of the pearl powder due to higher hydrophilicity resulted in more rapid release of the drug. Moreover, at certain pearl concentration (compared with the neat PLA), an improved antitumor efficacy was reported when the materials were seeded with HeLa tumor cells [10]. DOX was also loaded in poly(L-lactide-co-D,L-lactide) (CoPLA), and a synergistic action was reported when it was used in combination with quaternized chitosan (QCh) for the inhibition of human cervical tumor cell line HeLa. DOX easily penetrated the cells membranes due to the opposite charges of the tertiary amino groups of QCh and the areas of the tumor 


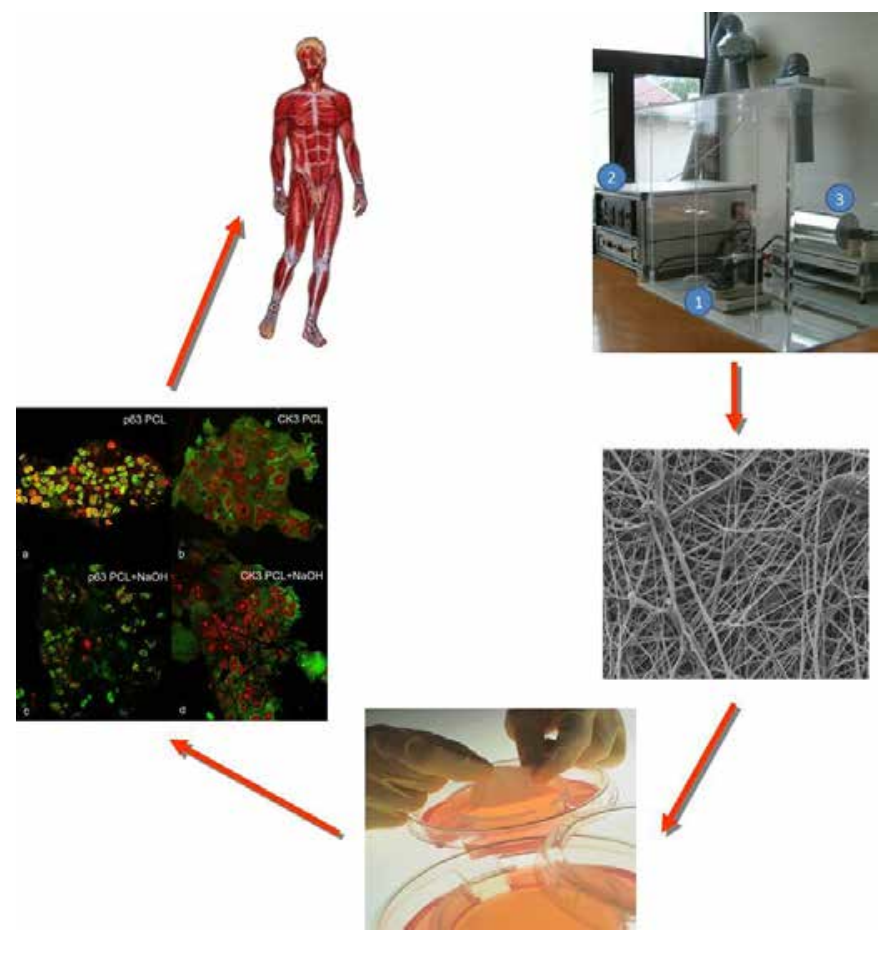

Figure 1. Stages in electrospun scaffold preparation and cell culture for tissue repair [4].

cells membranes that lead to their destruction [11]. Emulsion electrospun hydroxycamptothecin (HPCT)/poly(dl-lactic acid)poly(ethylene glycol) (PELA) fibers were used for the inhibition of the activity of cancer cell line HepG2. It was reported that during 72-h incubation, the incorporated drug showed 20 times higher inhibition against HepG2 cells than the free HCPT [12]. For skin wound healing, electrospun PCL/collagen scaffolds were loaded with androgen receptor (AR) inhibitor called ASC-J9. The study showed that the loaded active molecules can enhance skin cell growth, migration, differentiation and wound closure. Thus, the sustained release of the biofactor over 28 days improved fibroblasts adhesion and ingrowth, and it also accelerated wound closure by improved keratinocytes migration [13].

In this work, electrospun PCL scaffolds were loaded with the antibiotic cefuroxime (CFU) to be used in the therapeutic repair of eye tissues, especially after eye surgery. The scaffolds morphology, as well as their thermal and mechanical properties were evaluated depending on the loaded drug concentration. To verify the biocompatibility of the electrospun scaffolds, growth and viability of two different human cell lines were tested (HeLa and Hep G2). For that purpose, a standard 3-(4,5-dimethylthiazol-2-yl)-2,5-diphenyltetrazolium bromide (MTT) assay was applied after cell seeding and incubation on PCL scaffold samples. The assay is based on the conversion of soluble yellow tetrazolium salt into purple insoluble formazan crystals in the presence of metabolically active cells. In this relatively easy and fast way, variously produced scaffolds can be tested for their potential biomedical application. Similar approach of PCL-based scaffold testing has been carried out recently by some other researchers [14, 15]. Apart from medicine support function of the developed electrospun scaffold, this work contributes concerning comparison of the metabolic activity of the two forth-mentioned human cell lines.

\section{Experimental}

\subsection{Materials and methodology}

Materials used in this work were PCL with $\mathrm{Mn}=80,000$ (Lach:ner), antibiotic CFU (Astro Pharm) and solvents: glacial acetic acid and acetone (Ru-Ve). 10\% PCL polymer solution was prepared by dissolving the polymer in glacial acetic acid and acetone with the volume ratio of $8: 2$ with a constant stirring for at least $24 \mathrm{~h}$. The antibiotic CFU was added with the concentrations of $0.5 \%, 1 \%, 1.5 \%$ and $2 \%$ in $100 \mathrm{ml}$ of the polymer solution with further stirring and heating at $50^{\circ} \mathrm{C}$. As prepared, blend polymer/antibiotic solutions were electrospun on the electrospinning device NT-ESS-300, NTSEE Co. Ltd., South Korea. The processing conditions were as follows: electrical voltage of $15-16 \mathrm{kV}$, needle tip to collector distance of $15 \mathrm{~cm}$, volume flow rate of $1 \mathrm{ml} / \mathrm{h}$ and electrospinning time of $4 \mathrm{~h}$. The polymer was contained in a BD plastic syringe, with 21-G blunt needle.

\subsection{Characterization techniques}

\subsubsection{Electrospun surface structure observation}

Material surface structure was observed under scanning electron microscopy (SEM) FEG QUANTA 250, FEI. The samples were coated with a thin layer of gold/palladium to provide electrical conductivity before imaging. Fiber diameters and area of the pores were measured using ImageJ by randomly selecting fibers and pores on the surface of the SEMimaged samples.

\subsubsection{Thermal property analysis}

The thermal properties of the electrospun materials were evaluated using differential scanning calorimetry (DSC, Mettler Toledo DSC 822e). The samples (about 9-10 mg) were first heated from room temperature to $100^{\circ} \mathrm{C}$ (first run) under nitrogen stream, at a standard heating/cooling rate of $10^{\circ} \mathrm{C}$ $\mathrm{min}^{-1}$, annealed at $100^{\circ} \mathrm{C}$ for $5 \mathrm{~min}$ to erase thermal history. After heating, cooling was done using liquid nitrogen from $100^{\circ} \mathrm{C}$ to $-100^{\circ} \mathrm{C}$ at $10^{\circ} \mathrm{C} \mathrm{min}^{-1}$ and then second heating from $-100^{\circ} \mathrm{C}$ to $100^{\circ} \mathrm{C}$. Measurement was conducted in a nitrogen stream at a flow rate of $40 \mathrm{ml} / \mathrm{min}$. The DSC curves were used to determine characteristic transitional temperatures and heat enthalpies.

\subsubsection{Tensile testing}

Materials tensile tests were conducted on dynamometer (Statimat M, Textechno). The test conditions were a maximal force of $100 \mathrm{~N}$, a grip distance of $75 \mathrm{~mm}$ and a test speed of $25 \mathrm{~mm} / \mathrm{min}$. The samples were cut in $10 \mathrm{~mm} \times 100 \mathrm{~mm}$ and tested in triplicates. 


\subsubsection{Cell seeding}

Two standardly used human cell lines were applied in this work for PCL scaffold biocompatibility testing: HeLa and Hep G2. Both cell lines are of epithelial type and have originated from human cancerous tissue, cervix and liver, respectively. The cell inoculum for scaffold seeding was produced in Petri dish with DMEM culture medium and $10 \%$ fetal bovine serum, incubated at $37^{\circ} \mathrm{C}$ and humidified atmosphere composed of $95 \%$ air and $5 \% \mathrm{CO}_{2}$. Before cell seeding, the produced scaffold sheet was cut into circular-shaped discs that were embedded in wells of 24-well plate. The scaffold sheets were cleaned there and sterilized by soaking in $70 \%$ ethanol and exposed to UV light under laminar-flow hood for $60 \mathrm{~min}$. The ethanol was removed from the plate, and discs were washed twice in culture medium with serum. The cell inoculum was harvested form Petri dish using $0.25 \%$ trypsin (Sigma) and set to concentration of 100,000 cells $/ \mathrm{ml}$. Into each well, $0.5 \mathrm{ml}$ of cell inoculum was added. The plate was left static inside the incubator for cells to attach. After $6 \mathrm{~h}$, the culture medium with unattached cells was replaced with the fresh one. The plate was incubated inside the incubator for the next $72 \mathrm{~h}$. After 24- and 72- h postseeding, three discs of both types (PCL and $\mathrm{PCL}+\mathrm{CFU}$ ) were taken out and underwent standard MTT assay [16]. The discs were subsequently visually inspected for the development of purple color. The control discs were not seeded with cells but were incubated in culture media and MTT assay treated.
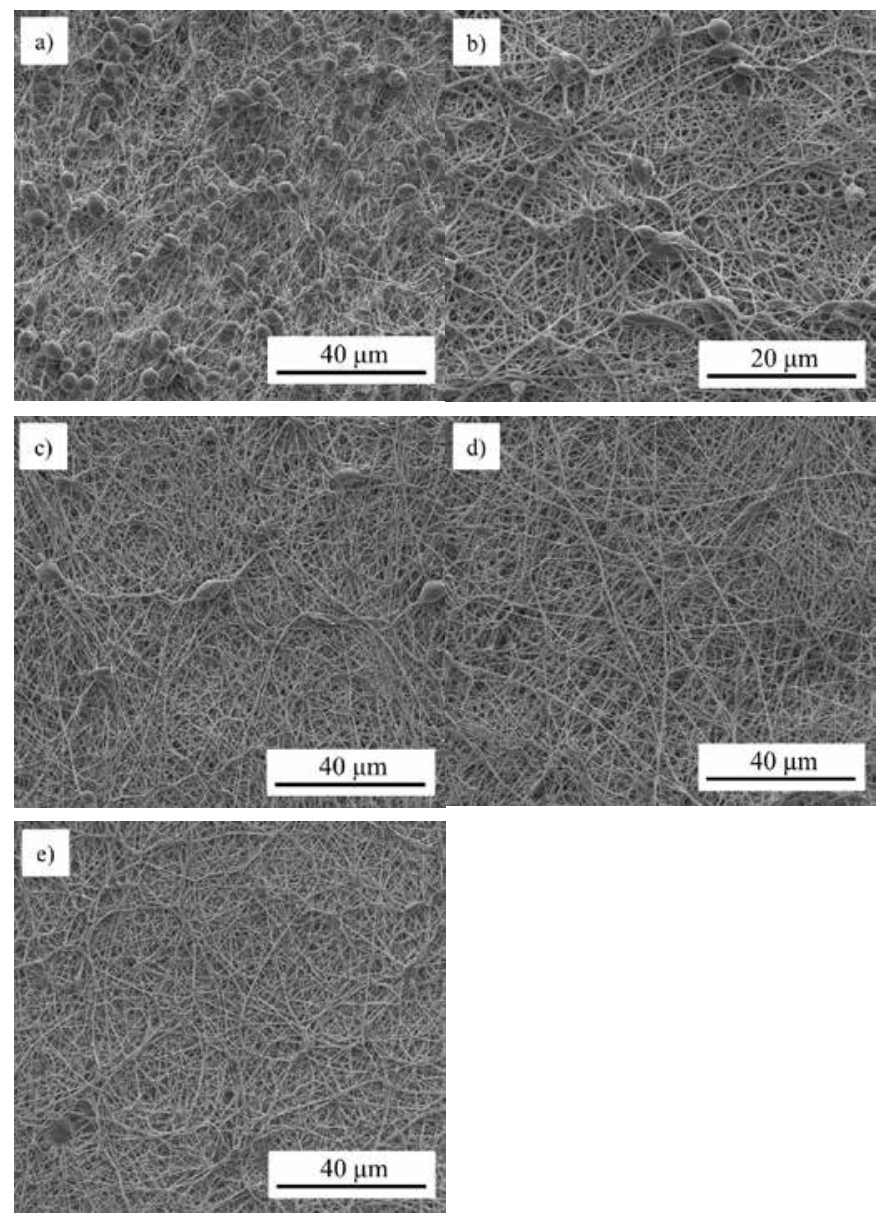

Figure 2. SEM images of the electrospun scaffolds: (a) neat PCL, (b) $\mathrm{PCL} / 0.5 \% \mathrm{CFU}$, (c) PCL/1\% CFU, (d) PCL/1.5\% CFU and (e) PCL/2\% CFU.

\section{Results and discussion}

\subsection{Scaffold morphology depending on the added antibiotic}

In scaffold design, one of the first factors affecting cell adhesion is their surface and thus fiber morphology and pore sizes. These two parameters need to be in compliance with seeded cell sizes to enable their adhesion and further migration inside the scaffolds. Figure 2 shows the SEM images of the electrospun neat PCL and blended PCL/CFU scaffolds.

The scaffolds were successfully electrospun at all antibiotic concentrations, and thus fibers were collected for the neat PCL as well as PCL with $0.5 \%-2 \%$ added CFU. Generally, the observed SEM images showed cylindrical fibers with smooth surfaces. Some fibers also showed deformations or beads along their lengths with spherical shapes and stretched or elliptical shapes. The number of random spherical beads was the highest for the neat PCL (Figure 2a). The increase in the antibiotic concentration reduced the number of beads and resulted in bead elongation or even disappearance in the case of the PCL/2\% CFU scaffolds (Figure 2e).

Figure $3 a$ and $b$ shows the distribution of the fiber diameter and pore area. Generally, most of the fiber diameters were distributed between $100 \mathrm{~nm}$ and $700 \mathrm{~nm}$ with few fibers having diameters up to $1.6 \mu \mathrm{m}$. The increase in the CFU concentration reduced the fibers distribution, and thus the mean fiber diameter reduced gradually with the increase in the antibiotic concentration, i.e., from $750 \mathrm{~nm}$ (neat PCL) to $300 \mathrm{~nm}$ (PCL/2\% CFU). A study reported on the electrospun poly(L-lactic acid) (PLLA)/riluzole fibers showed that there was a decrease in fiber diameter, which is due to the fact that the diameter was dependent on the drug small molecules prior to the solution concentration. Thus, electrospinning is affected by both drug chemical properties and drug size (hydrodynamic volume) [17]. In contrast, the distributions of the area of the pores mostly overlapped for all electrospun PCL and PCL/CFU scaffolds, and generally, the area of the pores was in the range between $1 \mu \mathrm{m}^{2}$ and $7 \mu \mathrm{m}^{2}$. Some pores were measured to have areas above $8 \mu \mathrm{m}^{2}$ to almost $14 \mu \mathrm{m}^{2}$. Finally, it was concluded that the addition of the CFU did not affect the changes in the area of the pores, which means that the area of the pores measured was all between $3 \mu \mathrm{m}^{2}$ and $4 \mu \mathrm{m}^{2}$.

\subsection{Scaffold thermal behavior depending on the added antibiotic}

The DSC curves during heating and cooling of the electrospun neat PCL and PCL/CFU scaffolds are shown in Figure $4 a$ and b, respectively. Table 1 shows the characteristic temperatures (melting temperature $\left[T_{m}\right]$ and crystallization temperature $\left.\left[T_{\mathrm{c}}\right]\right)$ as well as enthalpy of melting $\left(\Delta H_{\mathrm{m}}\right)$ and enthalpy of crystallization $\left(\Delta H_{c}\right)$.

PCL as a semicrystalline polymer contains amorphous and crystalline phases, and depending on the parameters in the electrospinning process, the level of these phases will change with the electrostatic forces during electrospinning that affect 

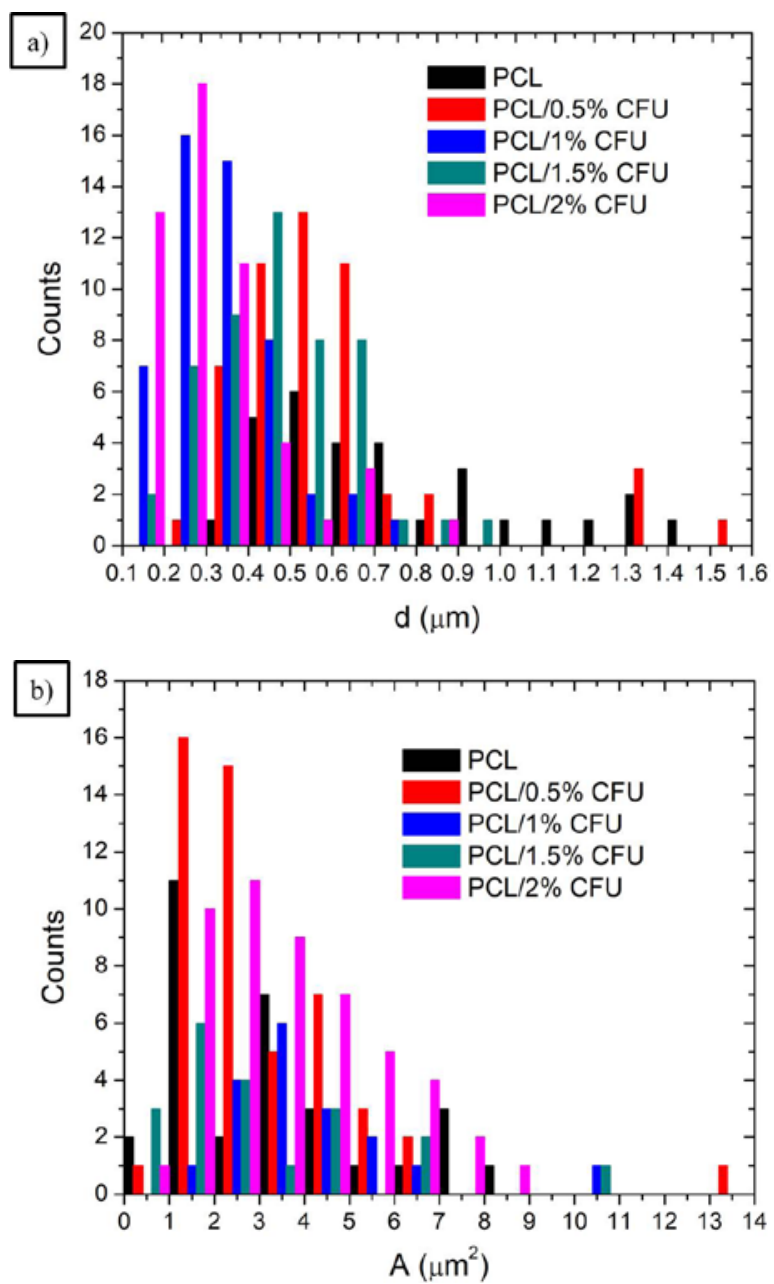

Figure 3. (a) Fiber diameter and (b) area of the pores distribution of the electrospun neat PCL and PCL/CFU scaffolds.

the degree of stretching of the PCL fibers. Similarly, a study reported on the effect of the electrical voltage change at different nozzle tip to collector distances on the degree of crystallinity of the electrospun PLLA fibers [18]. The addition of the antibiotic CFU in the electrospun PCL generally resulted in very small $\left(<1^{\circ} \mathrm{C}\right)$ change in the melting temperature $\left(T_{m}\right)$ of the $\mathrm{PCL}$ crystalline phase, with an exception for the $\mathrm{PCL} / 1 \% \mathrm{CFU}$ where the decrease in $T_{m}$ was from $56.78^{\circ} \mathrm{C}$ to $53.00^{\circ} \mathrm{C}$. Similarly, no changes in the $T_{\mathrm{m}}$ were reported when dexamethasone was encapsulated in PCL electrospun fibers [19].

This suggests that the highest decrease in the order of the PCL crystalline structure was achieved at $1 \%$ of the added antibiotic. In contrast, the higher shift (increase) in the crystallization temperature $\left(T_{\mathrm{c}}\right)$ was observed for all antibiotic concentrations with no significant changes when the antibiotic
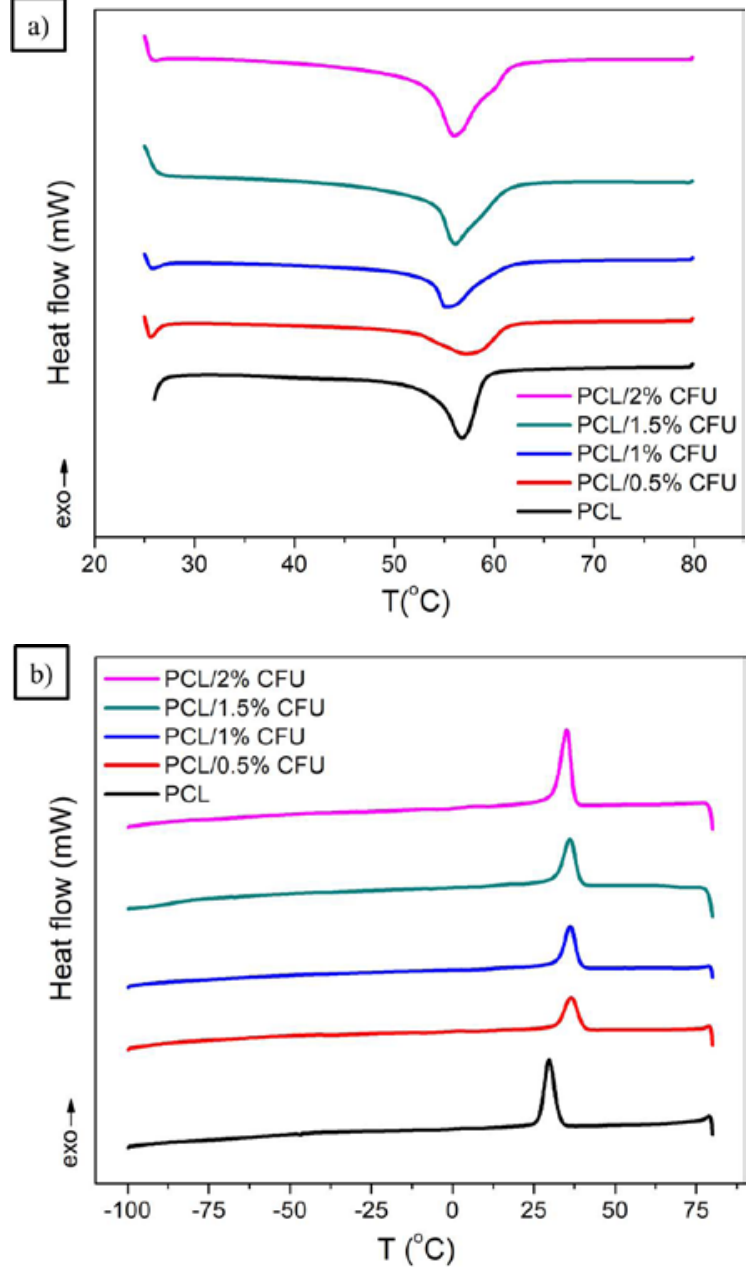

Figure 4. (a) DSC curves of the electrospun PCL and PCL/CFU scaffolds during melting and (b) crystallization.

concentration increased. This increase in $T_{c}$ suggested on the faster crystallization with the addition of antibiotic CFU.

Figure 5 gives the heating DSC curve of the antibiotic CFU where the $T_{m}$ of the antibiotic was observed at $174.66^{\circ} \mathrm{C}$. In the electrospun PCL/CFU scaffolds, no peak appeared around the $T_{\mathrm{m}}$ of the antibiotic, and thus the heating was conducted up to $80^{\circ} \mathrm{C}$. This suggests that the antibiotic is fully miscible with the polymer as confirmed by the single endothermic peak observed.

The addition of the antibiotic has significantly affected the scaffold enthalpies; although there was no regular trend with regard to the increased CFU content, the presence of the antibiotic has decreased the melting $\Delta H_{\mathrm{m}}$ and crystallization $\Delta H_{\mathrm{c}}$ enthalpies of the scaffolds. The highest decrease in the

Table 1. Temperatures and enthalpies of melting and crystallization

\begin{tabular}{|c|c|c|c|c|}
\hline Electrospun scaffolds & $\mathrm{T}_{\mathrm{m}}\left({ }^{\circ} \mathrm{C}\right)$ & $\mathrm{T}_{\mathrm{c}}\left({ }^{\circ} \mathrm{C}\right)$ & $\Delta H_{m}(J / g)$ & $\Delta \mathrm{H}_{\mathrm{c}}(\mathrm{J} / \mathrm{g})$ \\
\hline PCL & 56.78 & 29.72 & 84.29 & 72.36 \\
\hline PCL/0.5\% CFU & 57.30 & 36.37 & 47.84 & 40.33 \\
\hline $\mathrm{PCL} / 1 \% \mathrm{CFU}$ & 53.00 & 36.21 & 63.57 & 50.84 \\
\hline $\mathrm{PCL} / 1.5 \% \mathrm{CFU}$ & 56.10 & 36.22 & 73.84 & 46.46 \\
\hline
\end{tabular}




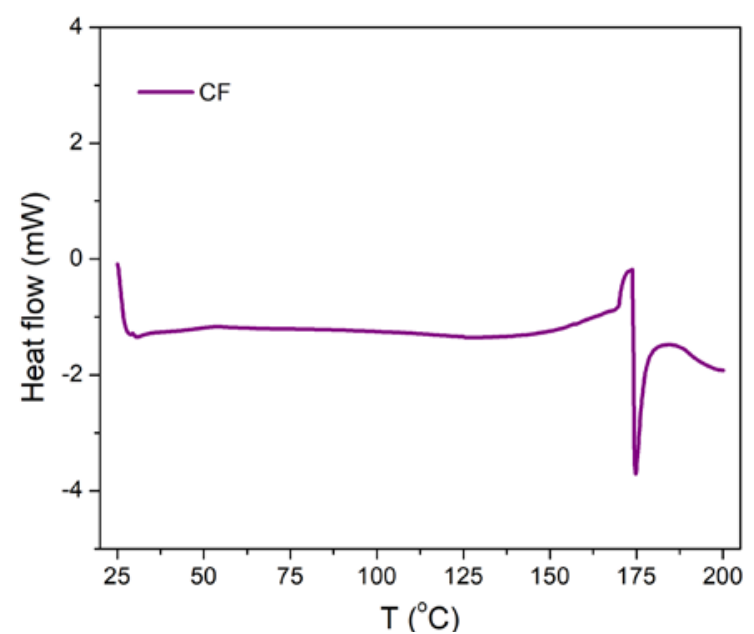

Figure 5. DSC curve of the cefuroxime during melting.

enthalpies was observed for the lowest CFU content, i.e., from $84.29 \mathrm{Jg}^{-1}$ to $47.84 \mathrm{Jg}^{-1}$ and from $72.36 \mathrm{Jg}^{-1}$ to $40.33 \mathrm{Jg}^{-1}$ for melting and crystallization, respectively. The lowest $\Delta H_{m}$ measured indicates highest reduction in the crystalline phase of the PCL. As the content of the CFU did not show a trend in the enthalpy change, this suggests that the distribution of the antibiotic in the polymer fibers differs with regard to homogeneity.

\subsubsection{Scaffold tensile behavior depending on the added antibiotic}

Figure 6 shows the tensile test behavior of the electrospun $\mathrm{PCL}$ and PCL/CFU scaffolds depending on the added antibiotic. Table 2 lists the break force, break strain and break stress of the electrospun PCL/CFU scaffolds. The force-strain curves of the electrospun scaffolds showed small breaks before materials final collapse due to the fiber slippage during each test. The mechanical integrity of the electrospun PCL/CFU scaffolds is very important for the scaffolds to withstand acting forces during cell growth or tissue formation. The results showed that the increase in the antibiotic concentration required higher force for the final collapse of materials. Highest break force was measured for the electrospun PCL/2\% CFU scaffolds of $505 \mathrm{cN}$, while the neat electrospun PCL scaffolds collapsed at $117 \mathrm{cN}$. The addition of the antibiotic also increased the break strength, with the highest of $6.824 \mathrm{MPa}$ for the PCL/1\% CFU scaffolds or eight times higher than the break strength of the neat PCL.

The strain change showed an opposite trend, and thus the increase in the antibiotic after the concentration of $0.5 \% \mathrm{CFU}$ has reduced the scaffold strain, down to $42.72 \%$. The irregular trend of change in the break strain and break strength suggests that the encapsulation of the antibiotic inside the fibers may vary with regard to homogeneous CFU distribution along the fibrous structure. In a study of electrospun PCL/PLGA (20/80), fibers loaded with a small molecule hydrophilic drug, tenofovir, the modulus and the tensile strength were not affected by the drug content up to $40 \mathrm{wt} \%$ of the drug loaded [20].

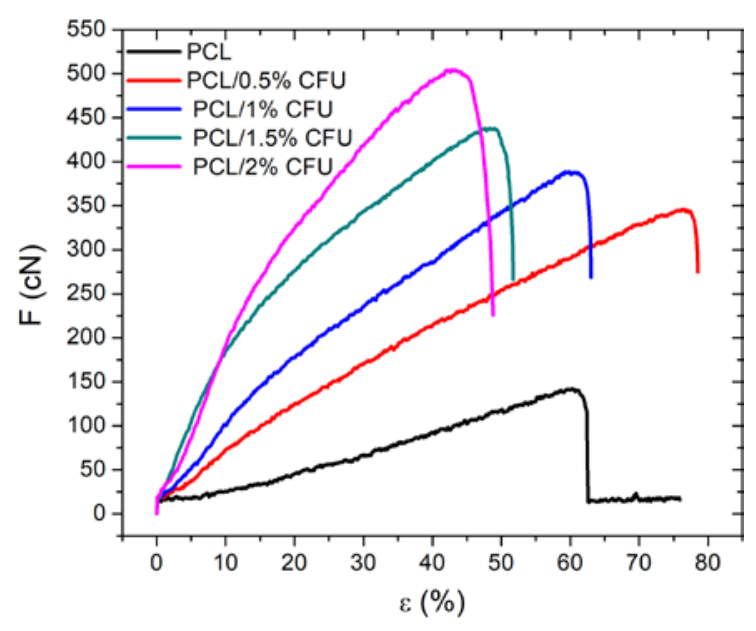

Figure 6. Tensile test behavior of the electrospun PCL/CFU scaffolds.

Table 2. Break force, break strain and break stress of the electrospun PCL/CFU scaffolds

\begin{tabular}{|c|c|c|c|}
\hline Electrospun scaffolds & $\mathbf{F}(\mathbf{c N})$ & $\boldsymbol{\varepsilon}(\%)$ & $\boldsymbol{\sigma}(\mathbf{M P a})$ \\
\hline PCL & 117 & 64.80 & 0.842 \\
\hline PCL/0.5\% CFU & 346 & 76.27 & 3.932 \\
\hline PCL/1\% CFU & 389 & 59.31 & 6.824 \\
\hline PCL/1.5\% CFU & 438 & 48.43 & 5.763 \\
\hline PCL/2\% CFU & 505 & 42.72 & 3.389 \\
\hline
\end{tabular}

\subsubsection{Comparison of the growth of two human cell lines}

Figure 7 shows PCL scaffolds seeded with two cell lines, HeLa (a) and Hep G2 (b) and a control disc without cells (c). All scaffolds are treated with MTT assay, and the resulting purple color indicates cell density and cell viability. Evidently both cell lines were successfully attached to the scaffold surface. However, HeLa cells showed somewhat better metabolic activity and faster growth rate and hence the development of more intense coloration. The seeding cell density was enough to cover most of the disc surface within $72 \mathrm{~h}$.

Therefore, the cells did not have much of leftover surface available to spread, and thus the increase of viable cell quantity over $72 \mathrm{~h}$ was not significant (i.e., not visually detectable). The presence of antibiotic CFU in scaffold composition expectedly did not affect cell attachment and survival. All these facts show that PCL scaffolds produced in aforementioned manner are compatible for growth of human cells and can be easily considered for further tests to improve their applicability in tissue repairment.

\section{Conclusion}

In this work, the preparation of electrospun PCL scaffolds incorporating antibiotic CFU to be used for human cell growth was investigated. The effect of the CFU content on the scaffolds properties was evaluated through scaffold morphology and thermal and mechanical properties. It was noted that the increase in the CFU content resulted in fiber 
HeLa

a)
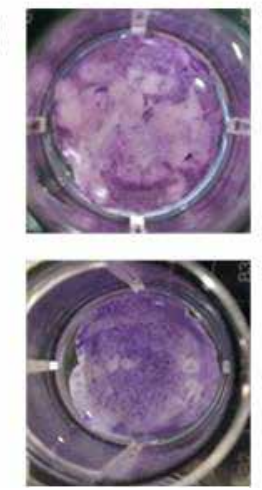
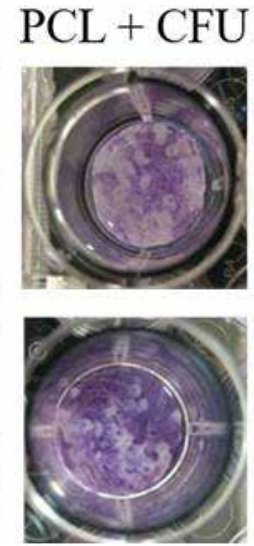

Hep G2

PCL PCL + CFU

b)

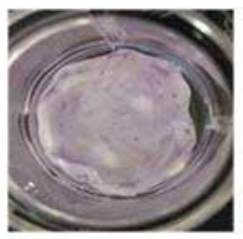

$72 \mathrm{~h}$

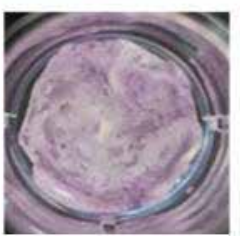

Control

PCL

c)

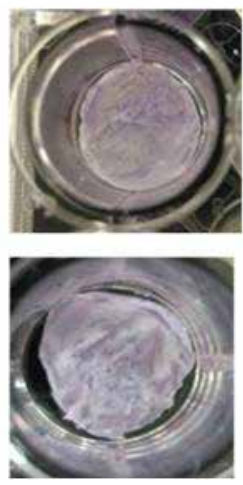

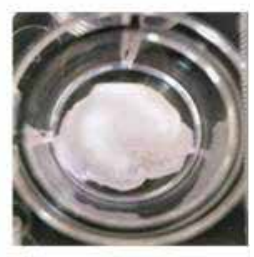

Figure 7. Testing PCL scaffolds with and without CFU for human cell growth. Two human cell lines were seeded on scaffold surface: (a) HeLa and (b) Hep G2. A scaffold without cells was used as (c) a control specimen. Standard MTT assay was applied for visual detection of cell viability and density 24 and $72 \mathrm{~h}$ after the seeding.

beads disappearance, fiber diameter distribution reduction, and thus fiber mean diameter decreases from $\sim 750 \mathrm{~nm}$ (neat $\mathrm{PCL}$ ) to $300 \mathrm{~nm}$ (PCL/2\% CFU), while in the case of area of the pores, no influence on the same was noted (area of the pores remained between $3 \mu \mathrm{m}^{2}$ and $4 \mu \mathrm{m}^{2}$ ). With regard to scaffold thermal properties, the addition of the CFU confirmed miscibility of the antibiotic and the polymer, and the reduction of the enthalpy of melting to almost half of the initial value suggested reduction of the fiber crystalline phase. The addition of the CFU improved scaffold break strength, with the highest measured of $6.824 \mathrm{MPa}$ for the electrospun $\mathrm{PCL} / 1 \% \mathrm{CFU}$ scaffolds. This suggests that the mechanical integrity of the scaffolds is not compromised by the addition of the antibiotic, thus will withstand the forces acting on it during tissue growth. The model cells used, HeLa and Hep G2, were both supported with regard to cell adhesion and spreading, and thus the PCL/ CFU scaffolds provided compatibility for human cells growth, with precedence in greater colonization of the HeLa cells. This model will be further used for the design of scaffolds for tissue repair.

\section{Acknowledgements}

This work has been fully supported by Croatian Science Foundation under the project IP-2016-06-6878, Custom Tailored Fibrous Scaffold Prototype for Tissue Cells Culture via Combined Electrospinning, COMBOELECTROSPUN.

\section{References}

[1] Zdraveva, E., Fang, J., Mijovic, B., Lin, T. (2016). Structure and properties of high-performance fibers; (Bhat, G., ed.) Woodhead Publishing in Association with the Textile Institute, by Elsevier: Cambridge.

[2] Mijović, B., Tominac Trcin, M., Agić, A., Zdraveva, E., Bujić, M., et al. (2012). Study on Cell Adhesion Detection onto Biodegradable Electrospun PCL Scaffolds. Journal of Fiber Bioengineering \& Informatics, 5(1), 33-40.
[3] Zdraveva, E., Magovac, E., Mijovic, B. (2016). Elektroispredanje - značajna tehnika 21. stoljeća. Tekstil: časopis za tekstilnu tehnologiju i konfekciju, 65(11-12), 397-409.

[4] Tominac Trcin, M., Dekaris, I., Mijović, B., Bujić, M., Zdraveva, E., et al. (2015). Synthetic vs natural scaffolds for human limbal stem cell cultivation. Croatian medical journal, 56(3), 246-256.

[5] Stevens, M. M., George, J. H. (2005). Exploring and engineering the cell surface interface, Science, 310(5751), 1135-1138.

[6] Li Loh, Q., Choong, C. (2013). Three-dimensional scaffolds for tissue engineering applications: role of porosity and pore size. Tissue Engineering: Part B, 19(6), 485-502.

[7] He, J.-H., Liu, Y., Mo, L.-F., Wan, Y.-Q., Xu, L. (2008). Electrospun Nanofibres and Their Applications, iSmithers, Shawbury, Shrewsbury, Shropshire.

[8] Han, J., Chen, T.-X., Branford-White, C. J., Zhu, L.M. (2009). Electrospun shikonin-loaded PCL/PTMC composite fiber mats with potential biomedical applications. International Journal of Pharmaceutics, 382(1-2), 215-221.

[9] Ranganath, S. H., Wang, C.-H. (2008). Biodegradable microfiber implants delivering paclitaxel for post-surgical chemotherapy against malignant glioma. Biomaterials, 29(20), 2996-3003.

[10] Dai, J., Jin, J., Yang, S., Li, G. (2017). Doxorubicin-loaded PLA/pearl electrospun nanofibrous scaffold for drug delivery and tumor cell treatment. Matererials Research Express, 4(7), 075403-075500.

[11] Ignatova, M. G., Manolova, N. E., Toshkova, R. A., Rashkov, I. B., Gardeva, E., et al. (2010). Electrospun Nanofibrous Mats Containing Quaternized Chitosan and Polylactide with In Vitro Antitumor Activity against HeLa Cells. Biomacromolecules, 11(6), 1633-1645.

[12] Luo, X., Xie, C., Wang, H., Liu, C., Yan, S., et al. (2012). Antitumor activities of emulsion electrospun fibers with core loading of hydroxycamptothecin via intratumoral implantation. International Journal of Pharmaceutics, 425(1-2), 19-28. 
[13] Chong, C., Wang, Y., Maitz, P. K. M., Simanainen, U., Li, Z. (2013). An electrospun scaffold loaded with anti-androgen receptor compound for accelerating wound healing. Burns \& Trauma, 1(2), 95-101.

[14] Suga, T., Xuyen, N. T., Matsumoto, K., Jikei, M., Takahashi, $K$., et al. (2017). Enhanced proliferation of HeLa cells on PLLA-PCL and PLGA-PCL multiblock copolymers. Polymer Journal, 49(7), 567-573.

[15] Heydari, Z., Mohebbi-Kalhori, D., Afarani, M. S. (2017). Engineered electrospun polycaprolactone (PCL)/ octacalcium phosphate (OCP) scaffold for bone tissue engineering. Materials Science \& Engineering. C Materials for Biological Applications, 81, 127-132.

[16] Denizot, F., Lang, R. J. (1986). Rapid colorimetric assay for cell growth and survival. Modifications to the tetrazolium dye procedure giving improved sensitivity and reliability. Journal of Immunological Methods, 89(2), 271-277.
[17] Johnson, C. D., D'Amato, A. R., Gilbert, R. J. (2016). Electrospun Fibers for Drug Delivery after Spinal Cord Injury and the Effects of Drug Incorporation on Fiber Properties. Cells Tissues Organs, 202(1-2), 116-135.

[18] Ero-Phillips, O., Jenkins, M., Stamboulis, A. (2012). Tailoring Crystallinity of Electrospun Plla Fibres by Control of Electrospinning Parameters. Polymers, 4(3), 13311348.

[19] Vacanti, N. M., Cheng, H., Hill, P. S., Guerreiro, J. D. T., Dang, T. T., et al. (2012). Localized Delivery of Dexamethasone from Electrospun Fibers Reduces the Foreign Body Response. Biomacromolecules, 13(10), 3031-3038.

[20] Chou, S.-F., Woodrow, K. A. (2017). Relationships between mechanical properties and drug release from electrospun fibers of PCL and PLGA blends. Journal of the Mechanical Behaviour of Biomedical Materials, 65, 724-733. 